\title{
SYNTHESIS OF NEW QUATERNARY AMMONIUM SALTS BASED ON MONOCHLOROACETIC ACID ESTERS
}

\author{
BAKHTIYOR BURIKHONOV ${ }^{1}$, TURSINALI KHOLIKOV ${ }^{2}$, ELYOR BERDIMURODOV ${ }^{3, *}$, HABIBULLA \\ TAJIMUHAMEDOV ${ }^{4} \&$ SHAHABUDDIN MEMON $^{5}$ \\ ${ }^{1}$ Student, Natural Sciences Department, Karshi State University, Karshi, Uzbekistan \\ ${ }^{2}$ Professor, Chemistry Department, National University of Uzbekistan, Tashkent, Uzbekistan \\ ${ }^{3}$ Professor, Natural Sciences Department, Karshi State University, Karshi, Uzbekistan \\ ${ }^{4}$ Professor, Chemistry Department, National University of Uzbekistan, Tashkent, Uzbekistan \\ ${ }^{5}$ Professor, National Centre of Excellence in Analytical Chemistry, University of Sindh, Jamshoro, Pakistan
}

\begin{abstract}
In this research, quaternary ammonium salts based on pyridine, 4-butylmorpholine with chloroacetic acid esters: nonyl 2-chloroacetate, benzyl 2-chloroacetate and pentan-2-yl 2-chloroacetate in the presence of ethyl acetate, acetone and ethyl alcohol solvents were synthesized, and then the modified synthesis methodology was first reported. The molecular structures of these salts were confirmed by IR and $H^{I}$ NMR spectroscopic techniques. It was found that the ethanol is productively a good solvent for the syntheses of new quaternary ammonium salts with over than $91 \%$ yield. The values of theoretical molecular descriptors and thermodynamic parameters of new synthesized quaternary ammonium salts were measured by DFT method. The obtained results indicate that the energy distinctions between the LUMO and HOMO of these salts are less than $0.3 \mathrm{eV}$, suggesting that new synthesized quaternary ammonium salt molecules are less stable and more reactive. The heat capacity and entropy of these organic compounds could be ranged as: $(103) 1>(85) 3>$ $(77) 4>(61) 2>(59) 6>(56) 5$, and it could be deduced that 1wasa higher heat capacity and more entropy molecule than the others.
\end{abstract}

KEYWORDS: Quaternary Ammonium Salts, N-Butylmorpholine, Pyridine, Esters \& Molecular Descriptors

Received: May 13, 2020; Accepted: Jun 03, 2020; Published: Aug 03, 2020; Paper Id.: IJMPERDJUN2020571

\section{INTRODUCTION}

In modern times, in the chemical industry, the synthesis of new types of quaternary ammonium salts is key of the more important aspects because; they are used as valuable surfactants, herbicides, disinfectants, deodorants, antistatic agents, dispersants, demulsifies, softeners and catalysts [1-4].

Quaternary ammonium salts can be synthesized from tertiary amines and chloroacetic acid esters. They are good water-soluble organic chemicals with many biological properties. Nitrogen atoms in the quaternary ammonium salts make them more water-soluble due to the presence of polarized centers. Thus, dipoles present in these salts make them more water-soluble. Another important aspect of the quaternary ammonium salts is that they have several biological active centers, which make the molecule have antimicrobial and anti-bactericidal properties. Therefore, the syntheses of quaternary ammonium salts are important to creating new biologically active drugs. However, herein quaternary ammonium salts (Breasted acidic ionic liquids) were synthesized from imidazole, pyridine, and benzyl chloride, which were used as effective catalysts for the syntheses of carboxylic esters [5-8]. 
In this research work, the synthesis of new quaternary ammonium salts based on tertiary amines and chloroacetic acid esters is reported. The synthesis methodology of the new organic compounds are based on pyridine, 4-butylmorpholine with chloroacetic acid esters: nonyl 2-chloroacetate, benzyl 2-chloroacetate and pentan-2-yl 2-chloroacetate in the presence of ethyl acetate, acetone, and ethyl alcohol solvents; these synthesized salts structure was proven by IR and $\mathrm{H}^{1} \mathrm{NMR}$ spectroscopic methods; FMO analyses measured the molecular descriptors and thermodynamic parameters of synthesized salts. These new quaternary ammonium salts and their derivatives have a wide range of chemical, physicochemical, pharmaceutical, antimicrobial, emulsifying, anti-corrosion, and anti-bactericidal properties. Besides, they may be used as cleaning materials, paints, emulsifiers, and moisturizers [9-12].

In addition to this, surfactants based on quaternary ammonium salts are used in the gas and oil industry as anticorrosion inhibitors. Quaternary ammonium salts can influence the cathodic and anodic reactions on the metal surface and thus reduce all corrosion processes in a corrosive environment. Because nitrogen atoms in these organic compounds cover and neutralize the metal surface, to form a thin protective layer[13-23].

\section{MATERIALS AND METHODS}

\subsection{Structural Analysis Method}

The IR and ${ }^{1} \mathrm{H}$ NMR were applied to confirm the structures of the studied organic molecules. ${ }^{1} \mathrm{H}$ NMR experiments were conducted using a Varian Unity 400 (+) JNM-4H-100 instrument. IR spectroscopic analysis was performedonSPECORD75 or Avator 360 spectrometers.

\subsection{Computational Methods}

The synthesized organic compounds were theoretically investigated using the modern quantum calculation method of DFT. In modern quantum calculation analysis, DFT is suitable for large organic molecules. The B3LYP method is used in DFT calculations of synthesized quaternary ammonium salts because the quaternary ammonium salts are large molecules and require large integral equations. The basis sets of 6-311G $(\mathrm{d}, \mathrm{p})$ were utilized in DFT calculations of the synthesized quaternary ammonium salts. Theoretically, thermodynamic parameters were measured at 298.150 K temperature [24-27].

\section{EXPERIMENTAL PART}

3.1 Synthesis of4-butyl-4-(2-(nonyloxy)-2-oxoethyl) morpholin-4-ium chloride

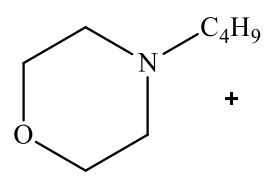

4-butylmorpholine

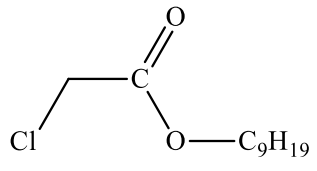

nonyl 2-chloroacetate

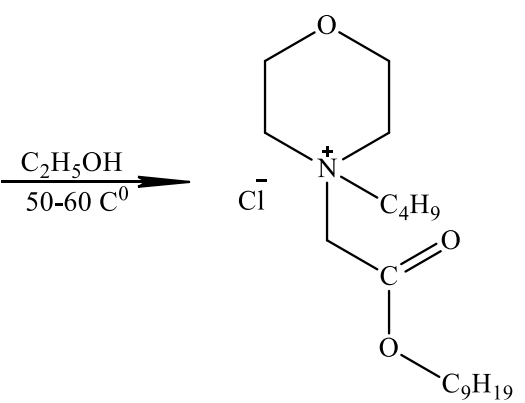

4-butyl-4-(2-(nonyloxy)-2oxoethyl)morpholin-4-ium chloride

$5.72 \mathrm{ml}(4.29 \mathrm{~g}, 0.03 \mathrm{~mol}$.) of 4-butylmorpholine was mixed with $6.125 \mathrm{ml}$ (6.615 g, $0.03 \mathrm{~mol}$.) of nonyl 2chloroacetatein the presence of $10 \mathrm{ml}$ ethyl alcohol solvent. The reaction yield was $91 \%$. $\mathrm{R}_{\mathrm{f}}=0.52$ (benzene:acetone $2: 1$ ratio),

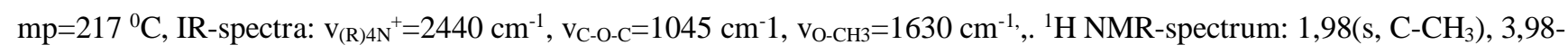


$3,86\left(\mathrm{t}, \mathrm{CH}_{2}-\mathrm{CH}_{2}-\mathrm{N}^{+}\right), 4,73-4,75\left(\mathrm{t}, \mathrm{O}-\mathrm{CH}_{2}-\mathrm{CH}_{2}\right), 2\left(\left(-\mathrm{CH}_{2}\right)_{8} \mathrm{CH}_{2}\right)_{2}, 4,17\left(4 \mathrm{H}, \mathrm{t}, \mathrm{J}=6.9 \mathrm{~Hz}, 1.48\left(\mathrm{~s} 6 \mathrm{H} 2 \mathrm{CH}_{3}\right)\right.$.

3.2 Synthesis of 4-(2-(benzyloxy)-2-oxoethyl)-4-butylmorpholin-4-ium chloride

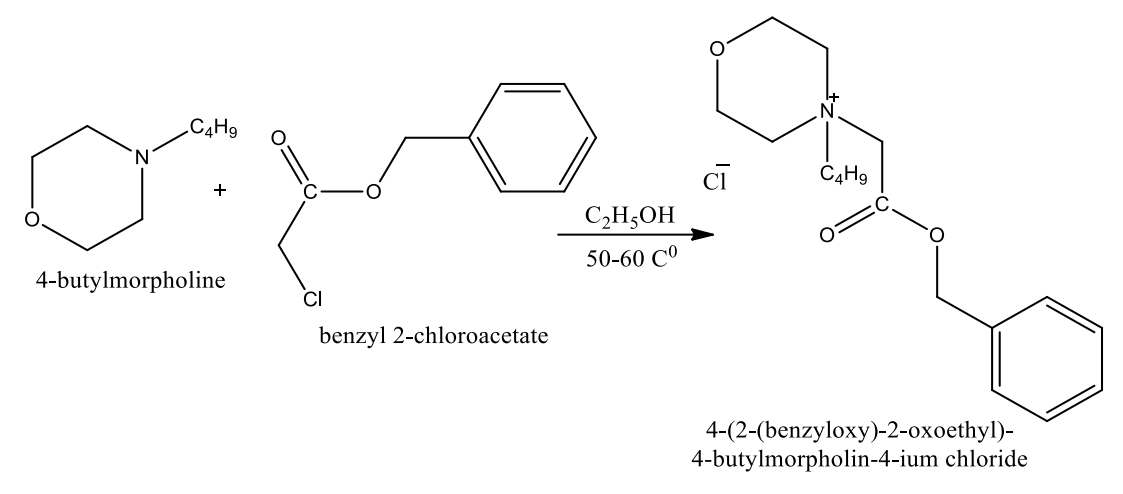

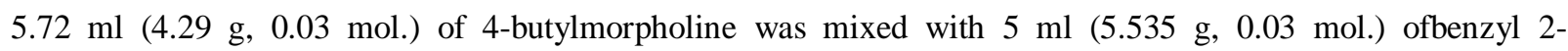
chloroacetatein the presence of $10 \mathrm{ml}$ ethyl alcohol solvent. The reaction yield was $92 \% . \mathrm{R}_{\mathrm{f}}=0.55$ (benzene : acetone $2: 1$ ratio), $\mathrm{mp}=225{ }^{0} \mathrm{C}$, IR-spectra: $\mathrm{V}_{4 \mathrm{~N}}{ }^{+}=2442 \mathrm{~cm}^{-1}, \mathrm{~V}_{\mathrm{C}-\mathrm{O}-\mathrm{C}}=1336 \mathrm{~cm}^{-1}, \mathrm{~V}_{\mathrm{C} 6 \mathrm{H} 5}=1452 \mathrm{~cm}^{-1},{ }^{1} \mathrm{H} \mathrm{NMR}$-spectrum: $1.39\left(\mathrm{~s}, 4 \mathrm{H}, \mathrm{CH}_{3}\right)$, 2.10 (br s4H(CH$)_{2}$ ), 3.56 (br s, $2 \mathrm{H} \mathrm{N}-\mathrm{CH}_{2}$ ), 3.88 (br s,2H N-CH$), 4.77(\mathrm{~s} 2 \mathrm{H} \mathrm{Ar} \mathrm{CH}$ ), 5.26 (d J=7.0 Hz, 1H, 5H), 7.29-7.35 (m 4H, ArH), 7.95 (d J=7.0Hz, 1H, 6H).

3.3 Synthesis of4-butyl-4-(2-oxo-2-(pentan-2-yloxy)ethyl)morpholin-4-ium chloride

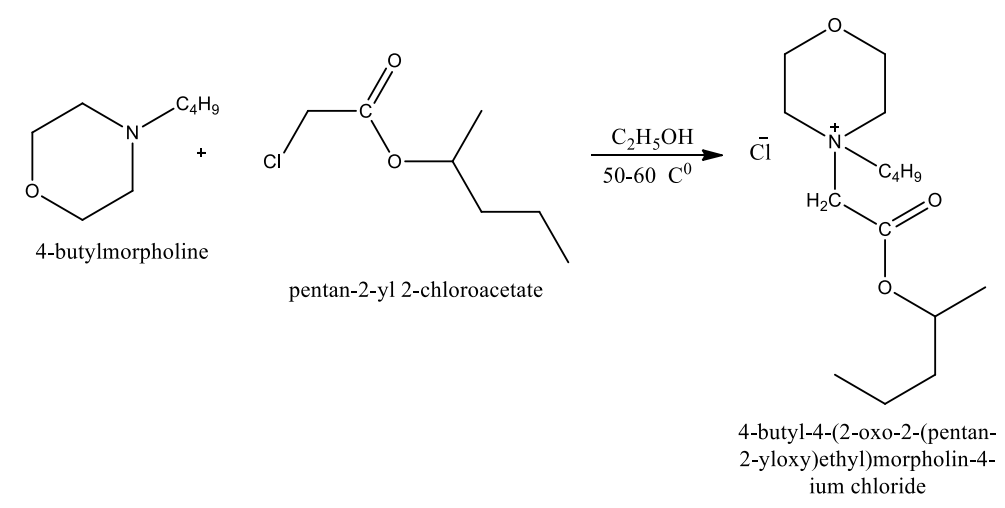

$5.72 \mathrm{ml}$ (4,29 g, $0.03 \mathrm{~mol}$.) of 4-butylmorpholine was mixed with $5 \mathrm{ml}$ (5.535 g. $0.03 \mathrm{~mol}$.) of 1-pentan-2-yl 2chloroacetatein the presence of $10 \mathrm{ml}$ ethyl alcohol solvent. The reaction yield was $92 \% . \mathrm{R}_{\mathrm{f}}=0.57$ (benzene : acetone $2: 1$

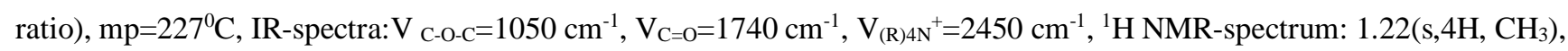
1.92-1.98(m, 4H ( $\left.\left.\mathrm{CH}_{2}\right)_{2}\right), 2.95$ (s, 2H, 3H), 3.53-3.56 (m, 2H N-CH $), 3.66-3.70\left(\mathrm{~m}, 2 \mathrm{H} \mathrm{N}-\mathrm{CH}_{2}\right), 5.28(\mathrm{~d} \mathrm{~J}=7.6 \mathrm{~Hz} 1 \mathrm{H}, 5 \mathrm{H})$, $7.36\left(\mathrm{dd}, \mathrm{J}=8.4,1.8 \mathrm{~Hz}, 1 \mathrm{H}, 3 \mathrm{CH}_{2}\right)$.

3.4 Synthesis of 1-(2-(nonyloxy)-2-oxoethyl) pyridin-1-ium chloride 
<smiles>c1ccncc1</smiles>

pyridine

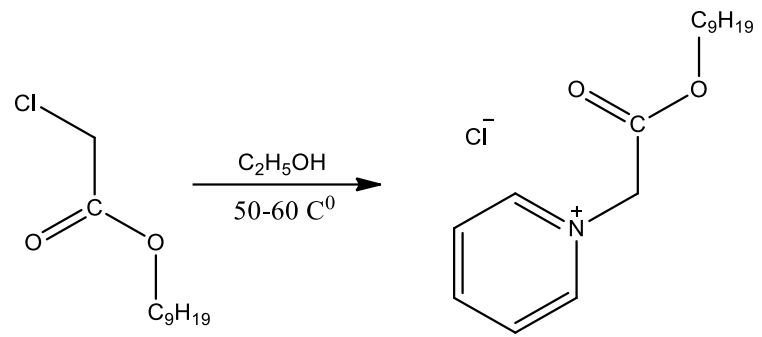

1-(2-(nonyloxy)-2-oxoethyl)pyridin-1-ium chloride

$2.4 \mathrm{ml}$ (2.37 g, 0.03mol.) of pyridine was mixed with $6.125 \mathrm{ml}$ (6.615 g. 0.03mol.) of nonyl 2-chloroacetatein the presence of $10 \mathrm{ml}$ ethyl alcohol solvent. The final product was dried in a desiccator for one day. The reaction yield was 92

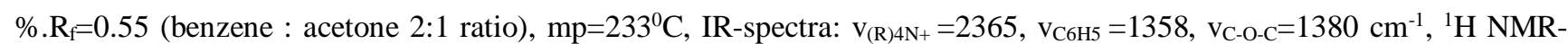

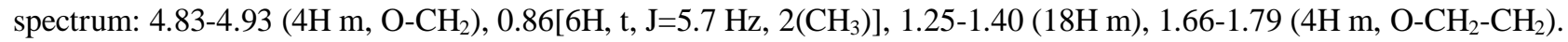

3.5 Synthesis of1-(2-(benzyloxy)-2-oxoethyl) pyridin-1-ium chloride

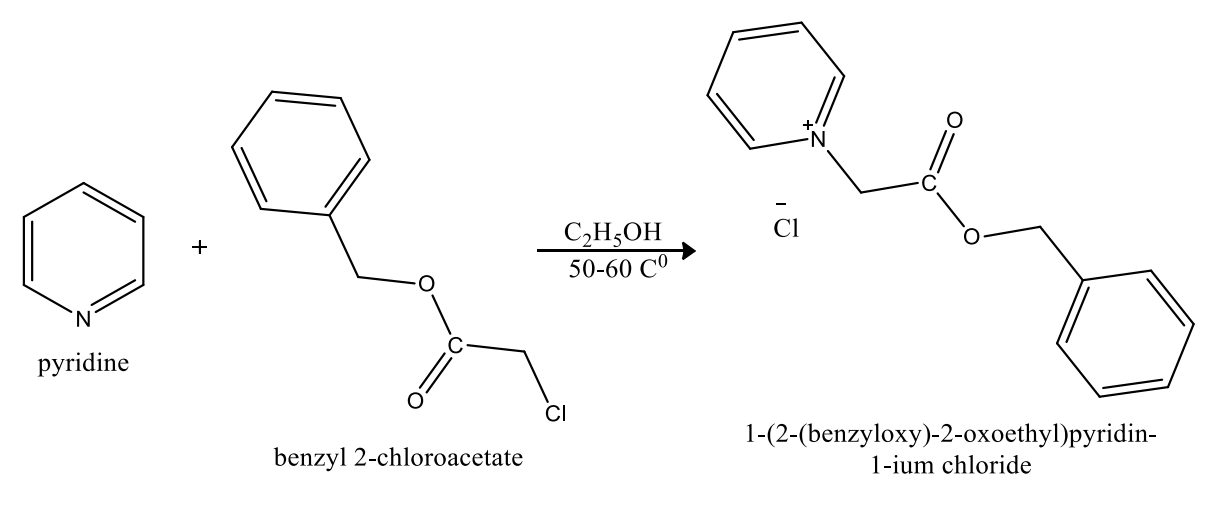

$4 \mathrm{ml}$ (3.95 g, $0.05 \mathrm{~mol}$.) of pyridine was mixed with $8.3 \mathrm{ml}$ (9.225 g. 0.05 mol.) of benzyl 2-chloroacetate in the presence of $15 \mathrm{ml}$ ethyl alcohol solvent. The final product was dried in a desiccator for 1 day. $\mathrm{R}_{\mathrm{f}}=0.63$ (benzene : acetone 2:1

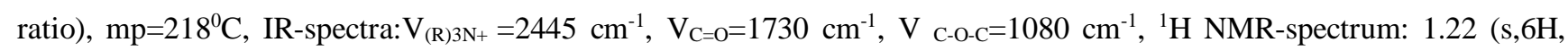
2 $\left.\mathrm{CH}_{3}\right), 1.93-1.96\left(\mathrm{~m}, 4 \mathrm{H},\left(\mathrm{CH}_{2}\right)_{2}\right), 3.51-3.54\left(\mathrm{~m}, 2 \mathrm{H}, \mathrm{N}-\mathrm{CH}_{2}\right), 4.76\left(\mathrm{~s}, 2 \mathrm{H}, \mathrm{Ar}-\mathrm{CH}_{2}\right), 5.25$ (d, J=7.0 Hz, 1H,5H), 7.20-7.24 (m, 2H,Ar-H), 7.38-7.42 (m, 2H, ArH), 7.82(d, J=7.0 Hz, 1H, 6H).

3.6 Synthesis of1-(2-oxo-2-(pentan-2-yloxy) ethyl)pyridin-1-ium chloride<smiles>c1ccncc1</smiles>

pyridine

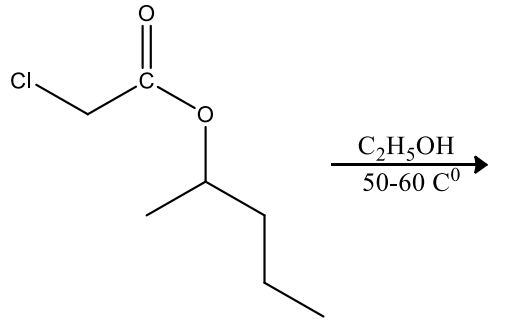

pentan-2-yl 2-chloroacetate<smiles>CCCC(C)OC(=O)C[n+]1ccccc1</smiles>

1-(2-oxo-2-(pentan-2yloxy)ethyl)pyridin-1-ium chloride 
$4 \mathrm{ml}$ (3.95 g, 0.05mol.) of pyridine was mixed with $7.45 \mathrm{ml}(8.225 \mathrm{~g}$. 0.05mol.) of pentan-2-yl 2-chloroacetate in the presence of $15 \mathrm{ml}$ ethyl alcohol solvent. The final product was dried in a desiccator for 1 day. $\mathrm{R}_{\mathrm{f}}=0.55$ (benzene : acetone 2:1 ratio), $\mathrm{mp}=220^{\circ} \mathrm{C}$, IR-spectra: $\mathrm{v}_{\mathrm{C}-\mathrm{O}-\mathrm{C}}=1120 \mathrm{~cm}^{-1}, \mathrm{v}_{\mathrm{C}=\mathrm{O}}=1640 \mathrm{~cm}^{-1}, \mathrm{v}_{(\mathrm{R}) 4 \mathrm{~N}}{ }^{+}=2380 \mathrm{~cm}^{-1},{ }_{1}^{1} \mathrm{H}$ NMR-spectrum: 1.27 (s, $5 \mathrm{H}$, $\left.\mathrm{CH}_{3}\right)$, 1.94-1.99 (m, 4H, $\left.\left(\mathrm{CH}_{2}\right)_{2}\right), 3.03$ (s, 2H,3H), 3.55(brt,J=6.2 Hz, 2H, N-CH $), 3.70\left(\right.$ br t, J=6.0 Hz, $\left.2 \mathrm{H} \mathrm{N}-\mathrm{CH}_{2}\right)$.

\section{RESULTS AND DISCUSSIONS}

\subsection{Syntheses Methodology}

In this study, new types of quaternary ammonium salts were synthesized based on pyridine and 4-butylmorpholine along with chloroacetic acid esters, i.e., nonyl 2-chloroacetate, benzyl 2-chloroacetate, and pentan-2-yl 2-chloroacetate.

At the first step of syntheses, chloroacetic acid esters, i.e., nonyl 2-chloroacetate, benzyl 2-chloroacetate, and pentan-2-yl 2-chloroacetate were synthesized by the following reaction scheme:

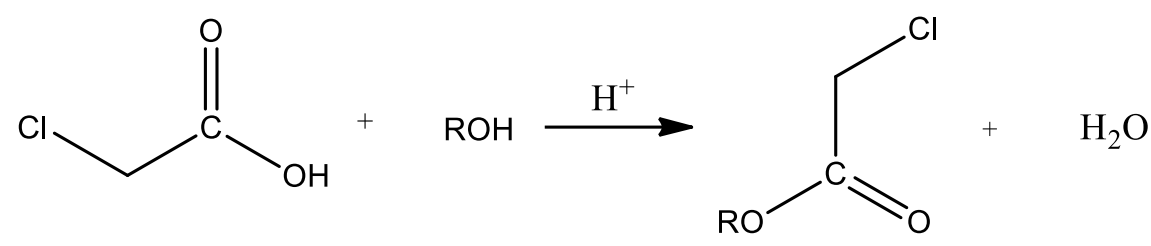

Where $\mathrm{R}=\mathrm{C}_{9} \mathrm{H}_{19^{-}}, \mathrm{i}-\mathrm{C}_{5} \mathrm{H}_{11^{-}}, \mathrm{C}_{6} \mathrm{H}_{5} \mathrm{CH}_{2-}$.

In this reaction scheme, chloroacetic acid was reacted with nonyl alcohol, benzyl alcohol and is opentyl alcohol in the concentrated sulfuric acid $\left(\mathrm{H}_{2} \mathrm{SO}_{4}\right)$ medium. $\mathrm{H}_{2} \mathrm{SO}_{4}$ is an effective catalyst in this reaction. In the final step, the reaction products of nonyl 2-chloroacetate, benzyl 2-chloroacetate, and pentan-2-yl 2-chloroacetate were formed. The reaction conditions are given in table 1. Concentrated sulfuric acid was used as the acid catalyst. The dependence of reaction productivity on the molar ratio of chloroacetic acid and alcohol was researched, and the observed data are depicted in table 1. The reaction between chloroacetic acid and both alcohols (i.e.,nonyl alcohol and is oamylalcohol )is over $75 \%$ productive at a 1:2 molar ratio.However, it can be seen from table 1 that the reaction yield is lower in the case of benzyl alcohol.

Table 1: Dependence of Reaction Productivity on the Molar Ratio of Chloroacetic Acid and Alcohols

\begin{tabular}{|l|c|c|}
\hline \multicolumn{1}{|c|}{ Alcohol } & $\begin{array}{c}\text { The Molar Ratio } \\
\text { Chloroacetic Acid:Alcohol }\end{array}$ & Reaction Yield (\%) \\
\hline \multirow{2}{*}{ Nonyl alcohol } & $1: 1$ & 65 \\
\cline { 2 - 3 } & $1: 2$ & 76 \\
\hline \multirow{2}{*}{ Benzyl alcohol } & $1: 1$ & 55 \\
\hline \multirow{2}{*}{ Isopentyl alcohol } & $1: 2$ & 58 \\
\cline { 2 - 3 } & $1: 1$ & 74 \\
\hline
\end{tabular}

It is clear from Table 1 that the reaction yield is more in the 1:2 molar ratio may be because many alcohol molecules increase the number of collisions in the esterification reaction. The reaction of nonyl alcohol and is opentyl alcohol with chloroacetic acid was more productive, relatively $76 \%$, and $78 \%$. Because nonyl and is opentyl radicals have positive induction effects. In contrast, thebenzyl alcoholreaction with chloroacetic acid is less productive, $58 \%$, because benzyl radicals have negative inductive and mesomeric effects, which can decrease oxygen electron affinity.

The next part of this research is the synthesis of new quaternary ammonium salts based on pyridine. The chloroacetic 
acid esters, i.e.,nonyl 2-chloroacetate, benzyl 2-chloroacetate, and pentan-2-yl 2-chloroacetate reacted with pyridine and 4butylmorpholine. All reactions were carried out in ethyl acetate, acetone, and ethyl alcohol solvents at reflux temperature.

Pyridine reacted with chloroacetic acid esters: nonyl 2-chloroacetate, benzyl 2-chloroacetate and pentan-2-yl 2chloroacetate related to the following reaction scheme:

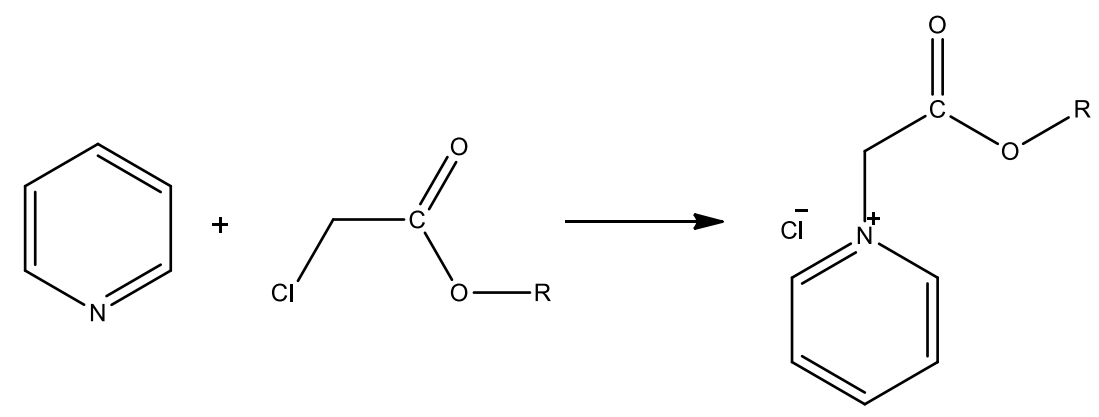

Where $\mathrm{R}=\mathrm{C}_{9} \mathrm{H}_{19^{-}}, \mathrm{i}-\mathrm{C}_{5} \mathrm{H}_{11^{-}}, \mathrm{C}_{6} \mathrm{H}_{5} \mathrm{CH}_{2-}$.

To conduct the above reaction, the first pyridine was mixed with chloroacetic acid esters in a solvent, and then this mixture heated for 3 hours. Finally, the yellow light solution formed, and then this solution was recrystallized in ethanol, and white crystals formed. The reaction conditions are illustrated in Table 2.

The following part of the investigation is the synthesis of new quaternary ammonium salts based on 4butylmorpholine. First, morpholine was alkylated with butyl bromide, and then 4-butylmorpholine was formed. The reaction was done related to the following scheme:
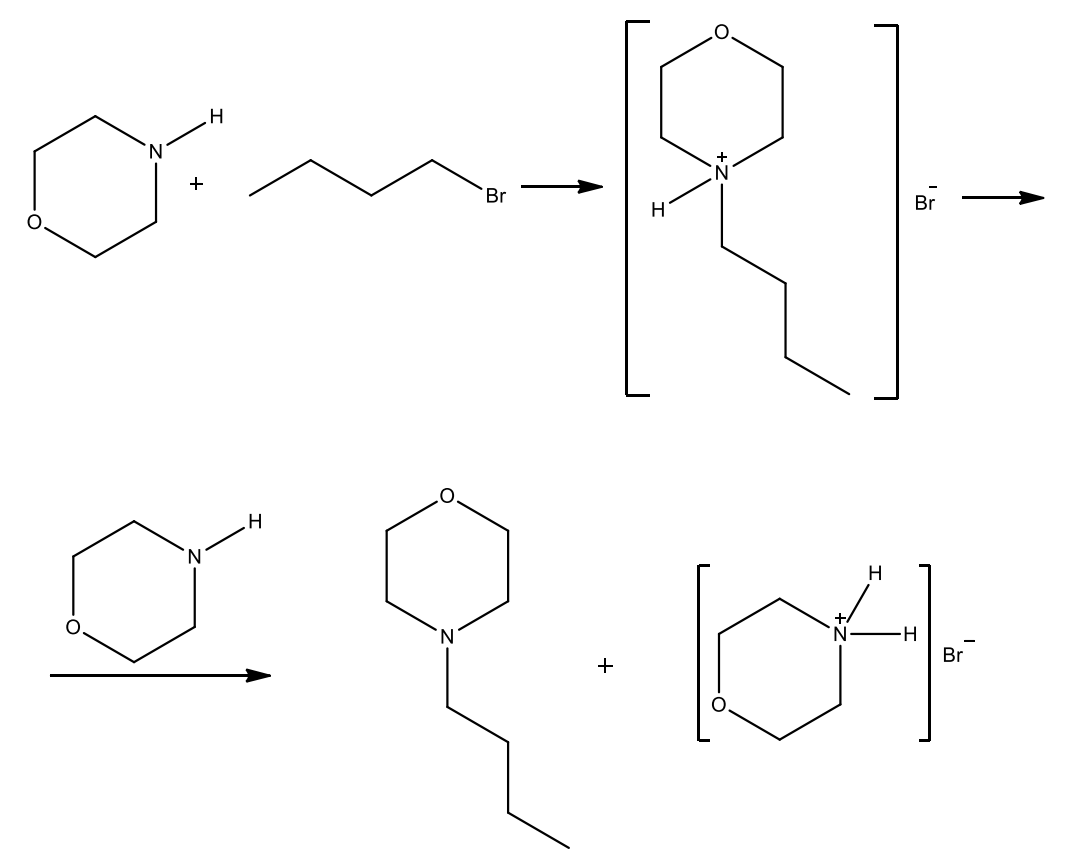

Morpholine was added to butyl bromide and heated at $120^{\circ} \mathrm{C}$ in the presence of dimethyl formamide. When a solid mass was formed, it was cooled, and $20 \% \mathrm{NaOH}$ was added. Because $\mathrm{NaOH}$ can react with morpholinehy drobromide in the final solution. Finally, the solid 4-butylmorpholine was filtered through a filtration funnel. The reaction yield was $54 \%$. The reaction conditions are illustrated in table 2. 
Second, 4-butylmorpholine was reacted with chloroacetic acid esters related to the following reaction scheme:

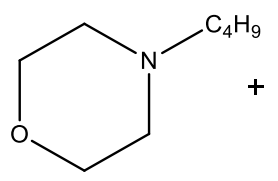<smiles>[R]OC(=O)CCl</smiles><smiles>CC(C)(C)O</smiles><smiles>[R]OC(=O)C[N+]1([13CH3])CCOCC1</smiles>

where $\mathrm{R}-\mathrm{C}_{9} \mathrm{H}_{19^{-}}, \mathrm{C}_{5} \mathrm{H}_{11^{-}}, \mathrm{C}_{6} \mathrm{H}_{5} \mathrm{CH}_{2-}$.

Table 2: Reaction Conditions of Pyridine with Chloroacetic Acid Esters in Different Solvents

\begin{tabular}{|c|c|c|c|c|c|c|}
\hline № & $\begin{array}{l}\text { Tertiary } \\
\text { Amine }\end{array}$ & Chloroacetic Acid Esters & Solvents & $\begin{array}{c}\text { Reaction Time } \\
\text { (hour) }\end{array}$ & Temperature & Yield, \% \\
\hline \multirow{3}{*}{1} & \multirow{9}{*}{ Pyridine } & \multirow{3}{*}{ Nonyl 2-chloroacetate } & ethyl acetate & 3 & Reflux & 61 \\
\hline & & & acetone & 3 & Reflux & 58 \\
\hline & & & $\begin{array}{l}\text { ethyl } \\
\text { alcohol }\end{array}$ & 3 & Reflux & 91 \\
\hline \multirow{3}{*}{2} & & \multirow{3}{*}{ Benzyl 2-chloroacetate } & ethyl acetate & 3 & Reflux & 65 \\
\hline & & & acetone & 3 & Reflux & 62 \\
\hline & & & $\begin{array}{l}\text { ethyl } \\
\text { alcohol }\end{array}$ & 3 & Reflux & 93 \\
\hline \multirow{3}{*}{3} & & \multirow{3}{*}{$\begin{array}{l}\text { Pentan-2-yl 2- } \\
\text { chloroacetate }\end{array}$} & ethyl acetate & 3 & Reflux & 61 \\
\hline & & & acetone & 3 & Reflux & 58 \\
\hline & & & $\begin{array}{l}\text { ethyl } \\
\text { alcohol }\end{array}$ & 3 & Reflux & 92 \\
\hline
\end{tabular}

Table 3: Reaction Conditions of 4-Butylmorpholine with Chloroacetic Acid Esters in Different Solvents

\begin{tabular}{|c|c|c|c|c|c|c|}
\hline № & Tertiary Amine & $\begin{array}{c}\text { Chloroacetic Acid } \\
\text { Esters }\end{array}$ & Solvents & $\begin{array}{l}\text { Reaction Time } \\
\text { (Hour) }\end{array}$ & Temperature & $\begin{array}{c}\text { Yield, } \\
\%\end{array}$ \\
\hline \multirow{3}{*}{4} & \multirow{9}{*}{$\begin{array}{l}\text { 4-Butyl- } \\
\text { morpholine }\end{array}$} & \multirow{3}{*}{ Nonyl 2-chloroacetate } & $\begin{array}{l}\text { ethyl } \\
\text { acetate }\end{array}$ & 3 & Reflux & 52 \\
\hline & & & acetone & 3 & Reflux & 56 \\
\hline & & & $\begin{array}{l}\text { ethyl } \\
\text { alcohol }\end{array}$ & 3 & Reflux & 91 \\
\hline \multirow{3}{*}{5} & & \multirow{3}{*}{ Benzyl 2-chloroacetate } & $\begin{array}{l}\text { ethyl } \\
\text { acetate }\end{array}$ & 3 & Reflux & 52 \\
\hline & & & acetone & 3 & Reflux & 54 \\
\hline & & & $\begin{array}{l}\text { ethyl } \\
\text { alcohol }\end{array}$ & 3 & Reflux & 92 \\
\hline \multirow{3}{*}{6} & & \multirow{3}{*}{$\begin{array}{l}\text { Pentan-2-yl 2- } \\
\text { chloroacetate }\end{array}$} & $\begin{array}{l}\text { ethyl } \\
\text { acetate }\end{array}$ & 3 & Reflux & 54 \\
\hline & & & acetone & 3 & Reflux & 52 \\
\hline & & & $\begin{array}{l}\text { ethyl } \\
\text { alcohol }\end{array}$ & 3 & Reflux & 91 \\
\hline
\end{tabular}

To conduct the above reaction, first, 4-butylmorpholine was mixed with chloroacetic acid esters in a solvent and refluxed for 3 hours. Finally, the light yellow solution formed was recrystallized in ethanol to obtain white crystals.

Tables 2 and 3 describe that the reaction of pyridine with chloroacetic acid esters was more productive in ethyl alcohol solvent than in ethyl acetate and acetone for several reasons: first, ethyl alcohol solvent is more polar, which easily breaks $\mathrm{Cl}-\mathrm{CH}_{2}$ bonds; second, ethyl acetate and acetone are less polar; third, the reaction product is a polar molecule that can 
easily be dissolved in a more polar solvent.

\subsection{Frontier Molecular Orbital Analyses}

In this research, frontier molecular orbital (FMO) tests were conducted using DFT. The FMO analysis indicates that the global reactivity properties of studied organic compounds, for example, the chemical softness, global electrophilicity index, chemical hardness, electronic chemical potential, and electronegativity of the synthesized researched chemical compounds. The obtained results are presented in Tables 4-10. The optimized molecular HOMO and LUMO are displayed in figures 112.

In the FMO theory, the LUMO and HOMO energies are equal to the electronic affinity and ionization potential, respectively. It was shown from Tables 4-9, the electronic affinity of the synthesized quaternary ammonium salts was ranged correspondingly: $2>6>5>1>3>4$, meaning that 2 and $\mathbf{6}$ quaternary ammonium salts are more electronic affinity molecules than others. Because the quaternary nitrogen atoms in $\mathbf{2}$ and $\mathbf{6}$ molecules arelinked with more electronic affinity functional groups, such as $-\mathrm{COOH}$ and $-\mathrm{C}_{6} \mathrm{H}_{5}$. These functional groups make molecules more reactive.

It is clear from the obtained results that the ionization potential of the synthesized quaternary ammonium salts ranged, respectively; $2>1>3>4>6>5$, suggesting that $\mathbf{2}$ and $\mathbf{1}$ quaternary ammonium salts are more electronic affinity molecules than the other. The reason is that the quaternary nitrogen atoms in $\mathbf{2}$ and $\mathbf{1}$ molecules are linked with more ionization radicals like ${ }^{*} \mathrm{C}_{4} \mathrm{H}_{9},{ }^{*} \mathrm{C}_{6} \mathrm{H}_{5}$. These radicals make the molecule more ionized.

In the FMO theory, the energy distinction between the LUMO and HOMO shows molecular stability. This energy distinction is called $\mathrm{Eg}$. If $\mathrm{Eg}$ is lower, the molecule is more stable and nonreactive. If Eg is lower, the molecule is nonstable and more reactive. The results in Tables 4-9 indicate that Egfor the researched chemical compoundsis lower than $0.3 \mathrm{eV}$, which means that the researched chemical compounds are lower stable and more reactive. The energy band ranges $2<1<$ $3<5<6<4$, suggesting that $\mathbf{2}, \mathbf{1}$, and $\mathbf{3 q u a t e r n a r y}$ ammonium salts molecules are more reactive and nonstable than others. Because they have nitrogen atoms which linked with four ${ }^{*} \mathrm{CH}_{2}$ radicals. Many electron accepter functional groups make molecules more negative. 2,1, And 3researched chemical compounds were formed by the reaction between 4butylmorpholine and esters, which make molecules more reactive and nonstable.

In the FMO theory, the chemical structural parameters are calculated regarding to Equations (1-5):

$$
\begin{aligned}
& \text { Chemical hardness, } \eta(\mathrm{eV})=\frac{\mathrm{E}_{\mathrm{LUMO}}(\mathrm{eV})-\mathrm{E}_{\text {HOMO }}(\mathrm{eV})}{2} \\
& \text { Electronegativity, } \chi(\mathrm{eV})=\frac{-\left(\mathrm{E}_{\mathrm{LUMO}}(\mathrm{eV})-\mathrm{E}_{\mathrm{HOMO}}(\mathrm{eV})\right)}{2} \\
& \text { Chemical softness, } \mathrm{s}(\mathrm{eV})=\frac{1}{2 \eta(\mathrm{eV})}
\end{aligned}
$$

Electronic chemical potential, $\mu(\mathrm{eV})=\frac{\mathrm{E}_{\mathrm{LUMO}}(\mathrm{eV})+\mathrm{E}_{\mathrm{HOMO}}(\mathrm{eV})}{2}$

Global electrophilicity index, $\omega(\mathrm{eV})=\frac{\mu^{2}(\mathrm{eV})}{2 \eta(\mathrm{eV})}$

In this research, the molecular descriptors for the $\mathbf{6}$ synthesized quaternary ammonium salts were computed by DFT, and results are displayed in Tables 4-9. The obtained FMO analysis results reveal that the molecular descriptor and reactivity 
property of the synthesized quaternary ammonium salts. The HOMO can donate the valent electrons to empty orbitals. The LUMO shows that the tendency of organic molecules to accept valent electrons. The green and red colors in the LUMO and HOMO of the researched chemical compounds show correspondingly positive and negative values of the LUMO and HOMO orbitals (figures1-12), which means that the valence and $\pi$ electrons covered around the benzene rings and nitrogen atoms in the synthesized quaternary ammonium salts.

The chemical hardness value shows the resistance degree of molecular change and deformation. The chemical softness is negative of the chemical hardness, andit is molecular changeable and deformation able degrees. The chemical hardness and softness values of the researched chemical compounds were computed by DFT quantum analysis, and the observed data have resulted in Tables 4-9. It is clear from the results that all researched chemical compounds are lower chemical hardness and softness organic molecules; results indicate that they are more changeable and reactive organic molecules.

The global electrophilicity index values of the synthesized quaternary ammonium salts were computed by DFT quantum analysis, resulted in Tables 4-10. The global electrophilicity index value is an indicator to calculate the quantity value of Lewis acid. It depends on the molecular structure and physical properties, such as the dipole moment, polarization, and solubility. The global electrophilicity index DFT calculations were performed in the gas phase. The results show that the global electrophilicity index values of the researched chemical compounds were lower at $0.3 \mathrm{eV}$, suggesting that they are weak Levis acid. Because the aromatic rings and $* \mathrm{CH}_{2}$ radicals reduced Lewis acid value in the researched chemical compounds. It was found that the following range of the global electrophilicity index values: $\mathbf{3}>\mathbf{6}>\mathbf{5}>\mathbf{1}>\mathbf{4}>\mathbf{2}$. 3 And6molecules more acidic than others, because the morpholine ring is linked with nitrogen atoms. 5, 1, 4and2 molecules have more benzene rings, which decrease the molecules' Levis acid values.

In this research, it was computed the theoretical thermodynamic values of the researched chemical compounds by DFT quantum analysis. All theoretical thermodynamic DFT experiments were conducted at 298.150 K temperature and gas phase. The theoretical dipole moment, polarizability, entropy, heat capacity, and thermal energy of the researched chemical compounds were computed; the results are given in Tables 4-9. The dipole moment and polarizability values indicate the inductive interaction between dipole and ions in the organic molecule. The results show that all synthesized quaternary ammonium are more polarized molecules in gas phases. From the DFT analysis, it was calculated the following variation: 6.8 (2) $>3.8$ (4) $>3.7(5)>3.4(6)>2.5(3)>2.3(\mathbf{1})$. The molecule of 2 is more polarized than others because it has an aromatic ring and aliphatic rings, which make it more polarized. The heat capacity and entropy of the synthesized quaternary ammonium saltsranged: (103) $1>(85) 3>(77) 4>(61) 2>$ (59)6 > (56)5.4-Butyl-4-(2-(nonyloxy)-2oxoethyl)morpholin-4-ium chloride quaternary ammonium salt has a high heat capacity and is more entropy molecule than others because it has the aromatic ring, $-\mathrm{C}_{4} \mathrm{H}_{9}$ radical and aliphatic ring, which make the molecule more heat capacity molecule.

Table 4: Energy Values of the Global Reactivity and

Thermodynamic Parameters for 1 (298.150 K)

\begin{tabular}{|l|c|}
\hline \multicolumn{1}{|c|}{ Parameters, $\mathbf{e V}$} & $\mathbf{1}$ \\
\hline $\mathrm{E}_{\text {HOMO }}$ & -0.19 \\
\hline $\mathrm{E}_{\text {LUMO }}$ & -0.12 \\
\hline Eg & 0.07 \\
\hline Electronic affinity & -0.12 \\
\hline Ionization potential & -0.19 \\
\hline
\end{tabular}




\begin{tabular}{|l|c|}
\hline$\eta$ & 0.035 \\
\hline$\chi$ & -0.035 \\
\hline$\omega$ & 0.343 \\
\hline$\mu$ & -0.155 \\
\hline \multicolumn{2}{|c|}{ Table 1: Contd,. } \\
\hline s & 14.285 \\
\hline Dipole moment, Debye & 2.331 \\
\hline Polarizability ( $\alpha$ ), a.u. & 217.009 \\
\hline E(UB3LYP), Hartree & -1026.989 \\
\hline E (Thermal), kcal/mol & 368.358 \\
\hline Entropy (S), cal/mol-kelvin & 206.171 \\
\hline Heat capacity (Cv), cal/mol-kelvin & 103.726 \\
\hline
\end{tabular}

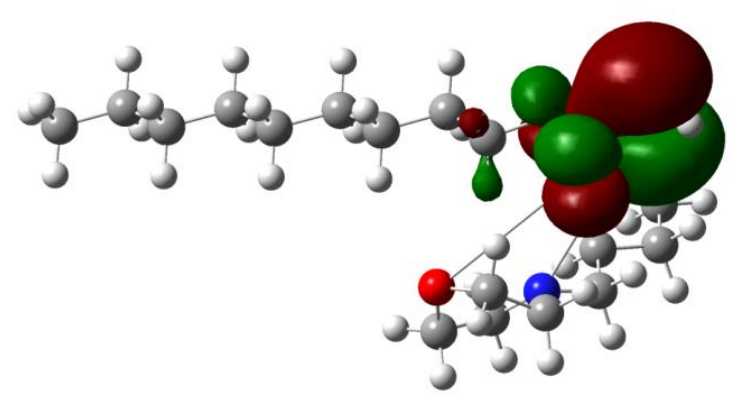

Figure 1: LUMO Orbitals of 1.

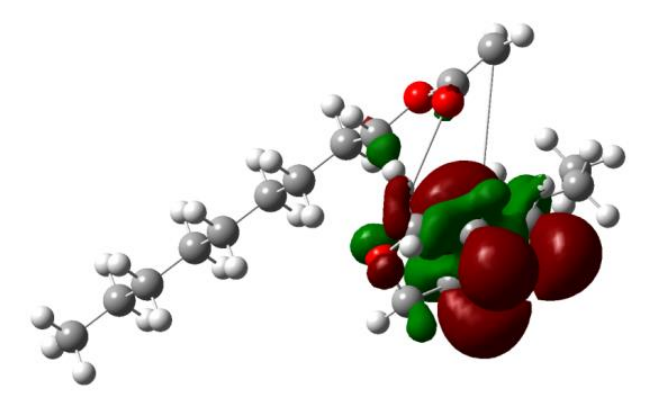

Figure 2: HOMO Orbitals of 1.

Table 5: Energy Values of the Global Reactivity and

Thermodynamic Parameters for 2 (298.150 K)

\begin{tabular}{|l|c|}
\hline \multicolumn{1}{|c|}{ Parameters, $\mathbf{e V}$} & $\mathbf{2}$ \\
\hline $\mathrm{E}_{\mathrm{LUMO}}$ & 0.023 \\
\hline $\mathrm{E}_{\text {HOMO }}$ & -0.040 \\
\hline $\mathrm{Eg}$ & 0.063 \\
\hline Electronic affinity & 0.023 \\
\hline Ionization potential & -0.040 \\
\hline$\eta$ & 0.0315 \\
\hline$\chi$ & -0.0315 \\
\hline$\omega$ & 0.00114 \\
\hline$\mu$ & -0.0085 \\
\hline $\mathrm{s}$ & 15.873 \\
\hline Dipole moment, Debye & 6.844 \\
\hline Polarizability $(\alpha)$, a.u. & 256.624 \\
\hline E(UB3LYP), Hartree & -943.056 \\
\hline
\end{tabular}




\begin{tabular}{|l|c|}
\hline E $($ Thermal), kcal/mol & 260.100 \\
\hline Entropy $(\mathrm{S}), \mathrm{cal} / \mathrm{mol}-\mathrm{kel}$ vin & 122.084 \\
\hline Heat capacity $(\mathrm{Cv}), \mathrm{cal} / \mathrm{mol}-\mathrm{kelvin}$ & 61.915 \\
\hline
\end{tabular}

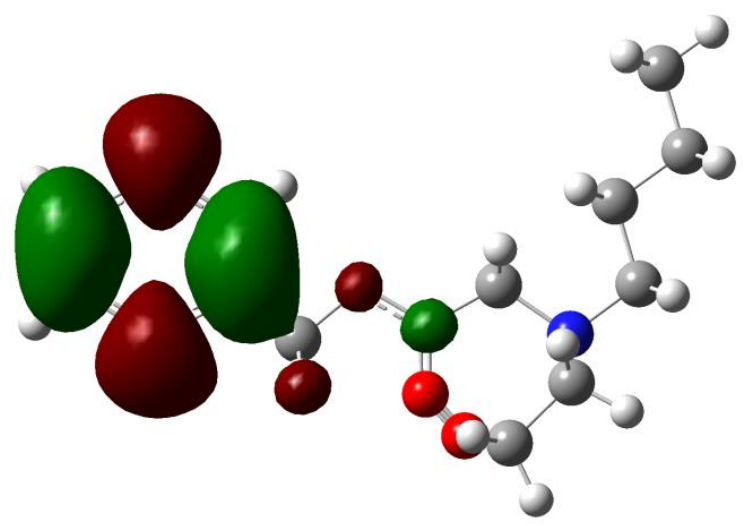

Figure 3: LUMO Orbitals of 2.

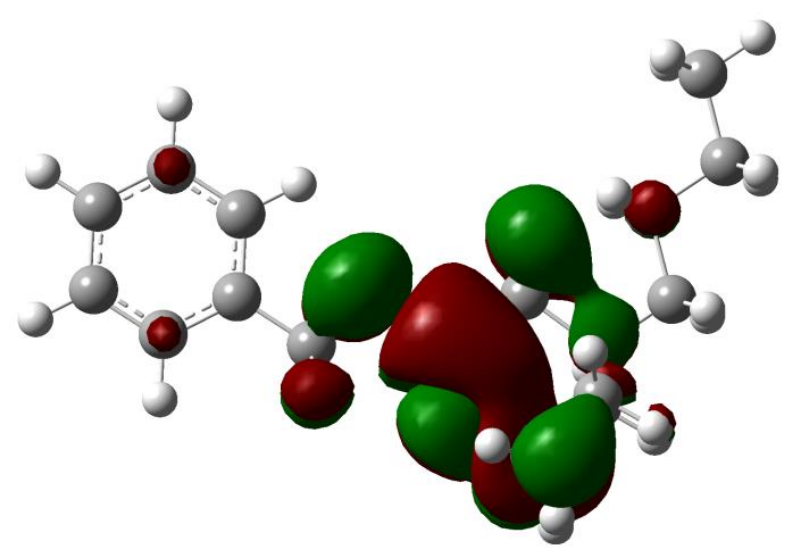

Figure 4: HOMO Orbitals of 2.

Table 6: Energy Values of the Global Reactivity and Thermodynamic Parameters for 3 (298.150 K)

\begin{tabular}{|l|c|}
\hline \multicolumn{1}{|c|}{ Parameters, $\mathbf{e V}$} & $\mathbf{3}$ \\
\hline $\mathrm{E}_{\text {LUMO }}$ & -0.115 \\
\hline $\mathrm{E}_{\text {HOMO }}$ & -0.195 \\
\hline Eg & 0.08 \\
\hline Electronic affinity & -0.115 \\
\hline Ionization potential & -0.195 \\
\hline$\eta$ & 0.04 \\
\hline$\chi$ & -0.04 \\
\hline$\omega$ & 0.3 \\
\hline$\mu$ & -0.155 \\
\hline$s$ & 12.5 \\
\hline Dipole moment, Debye & 2.528 \\
\hline Polarizability $(\alpha)$, a.u. & 173.706 \\
\hline E(UB3LYP), Hartree & -869.772 \\
\hline E (Thermal), kcal/mol & 292.364 \\
\hline
\end{tabular}




\begin{tabular}{|l|c|}
\hline $\begin{array}{l}\text { Entropy (S), cal/mol- } \\
\text { kelvin }\end{array}$ & 178.488 \\
\hline $\begin{array}{l}\text { Heat capacity }(\mathrm{Cv}), \\
\text { cal/mol-kelvin }\end{array}$ & 85.510 \\
\hline
\end{tabular}

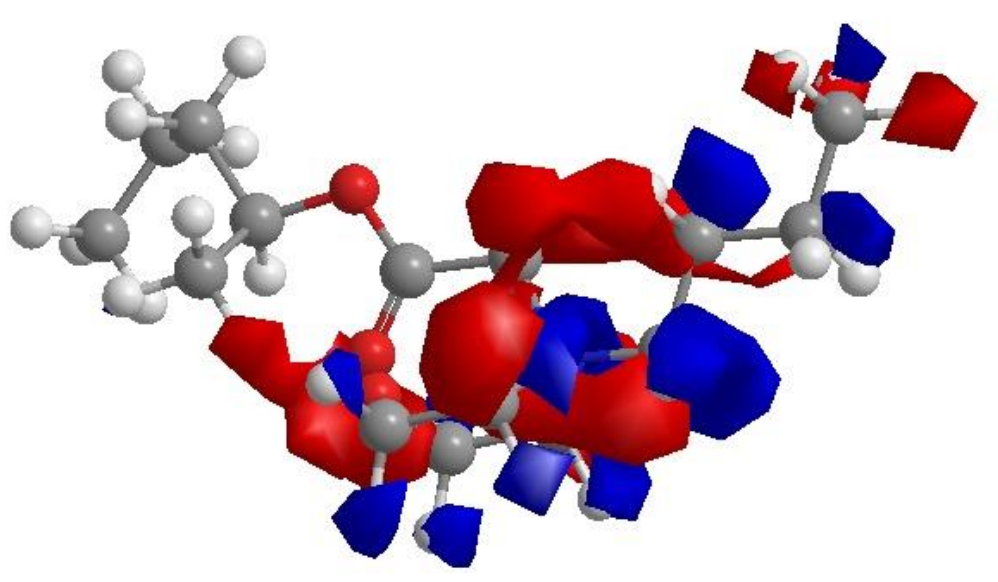

Figure 5: LUMO orbitals of 3.

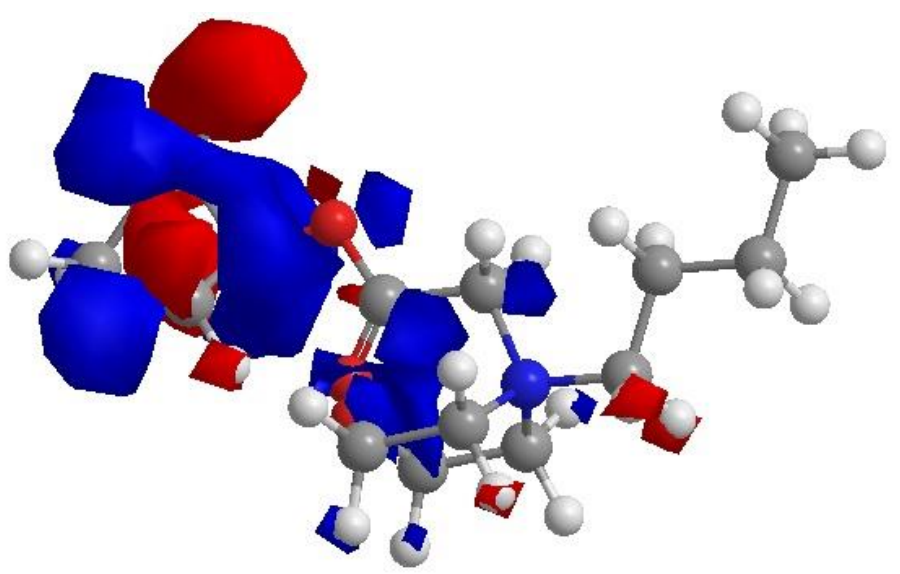

Figure 6: HOMO Orbitals of 3.

Table 7: Energy Values of the Global Reactivity and

Thermodynamic Parameters for $4(298.150 \mathrm{~K})$

\begin{tabular}{|l|c|}
\hline \multicolumn{1}{|c|}{ Parameters, eV } & $\mathbf{4}$ \\
\hline $\mathrm{E}_{\mathrm{LUMO}}$ & -0.134 \\
\hline $\mathrm{E}_{\mathrm{HOMO}}$ & -0.243 \\
\hline $\mathrm{Eg}$ & 0.377 \\
\hline Electronic affinity & -0.134 \\
\hline Ionization potential & -0.243 \\
\hline$\eta$ & 0.188 \\
\hline$\chi$ & -0.054 \\
\hline$\omega$ & 0.094 \\
\hline$\mu$ & -0.188 \\
\hline $\mathrm{s}$ & 2.652 \\
\hline Dipole moment, Debye & 3.683 \\
\hline Polarizability $(\alpha)$, a.u. & 180.533 \\
\hline E(UB3LYP), Hartree & -830.303 \\
\hline
\end{tabular}




\begin{tabular}{|l|c|}
\hline E (Thermal), kcal/mol & 264.389 \\
\hline Entropy (S), cal/mol-kelvin & 167.919 \\
\hline Heat capacity (Cv), cal/mol-kelvin & 77.357 \\
\hline
\end{tabular}

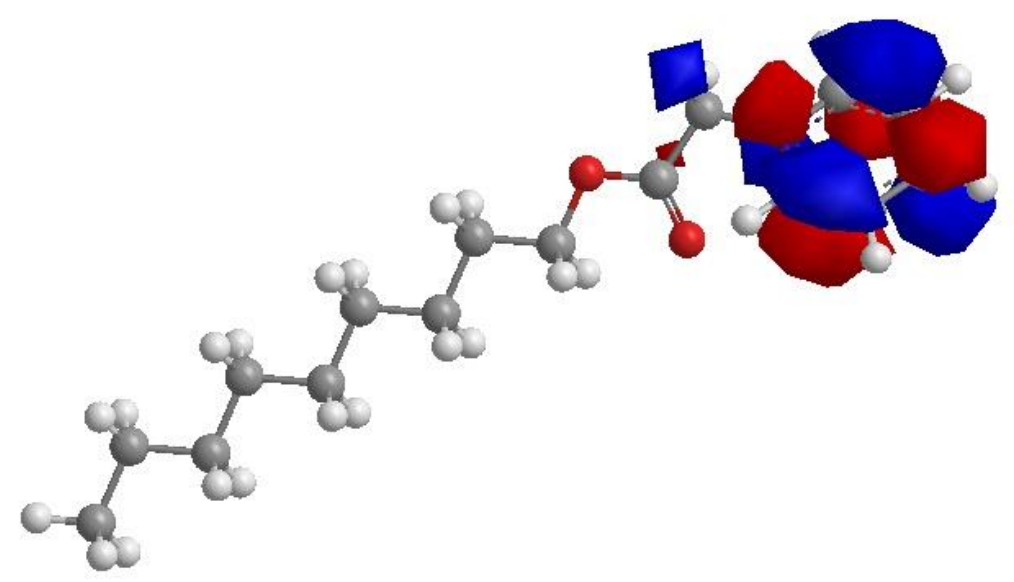

Figure 7: LUMO Orbitals of 4.

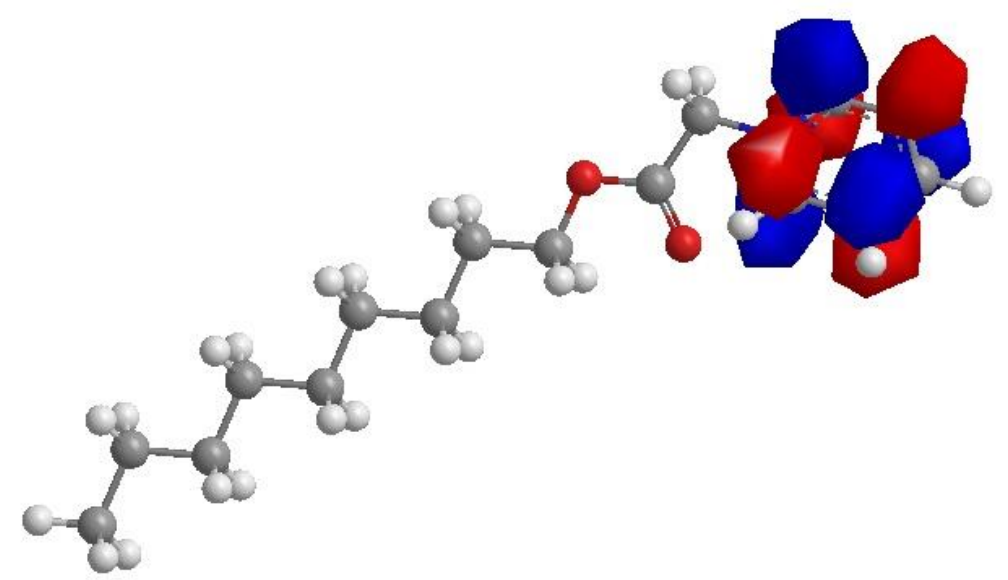

Figure 8: HOMO Orbitals of 4.

Table 8: Energy Values of the Global Reactivity and

Thermodynamic Parameters for 5 (298.150 K)

\begin{tabular}{|l|c|}
\hline \multicolumn{1}{|c|}{ Parameters } & $\mathbf{5}$ \\
\hline ELUMO $_{\text {Lu }}$ & -0.022 \\
\hline EHOMO $_{\text {HOM }}$ & -0.244 \\
\hline Eg & 0.222 \\
\hline Electronic affinity & -0.022 \\
\hline Ionization potential & -0.244 \\
\hline$\eta$ & 0.111 \\
\hline$\chi$ & -0.111 \\
\hline$\omega$ & 0.16 \\
\hline$\mu$ & -0.133 \\
\hline s & 4.5 \\
\hline Dipole moment, Debye & 3.7 \\
\hline Polarizability $(\alpha)$, a.u. & 154.83 \\
\hline E(UB3LYP), Hartree & -746.866 \\
\hline E (Thermal), kcal/mol & 167.636 \\
\hline
\end{tabular}




\begin{tabular}{|l|c|}
\hline Entropy $(\mathrm{S}), \mathrm{cal} / \mathrm{mol}-\mathrm{kelvin}$ & 138.503 \\
\hline Heat capacity $(\mathrm{Cv}), \mathrm{cal} / \mathrm{mol}-\mathrm{kelvin}$ & 56.803 \\
\hline
\end{tabular}

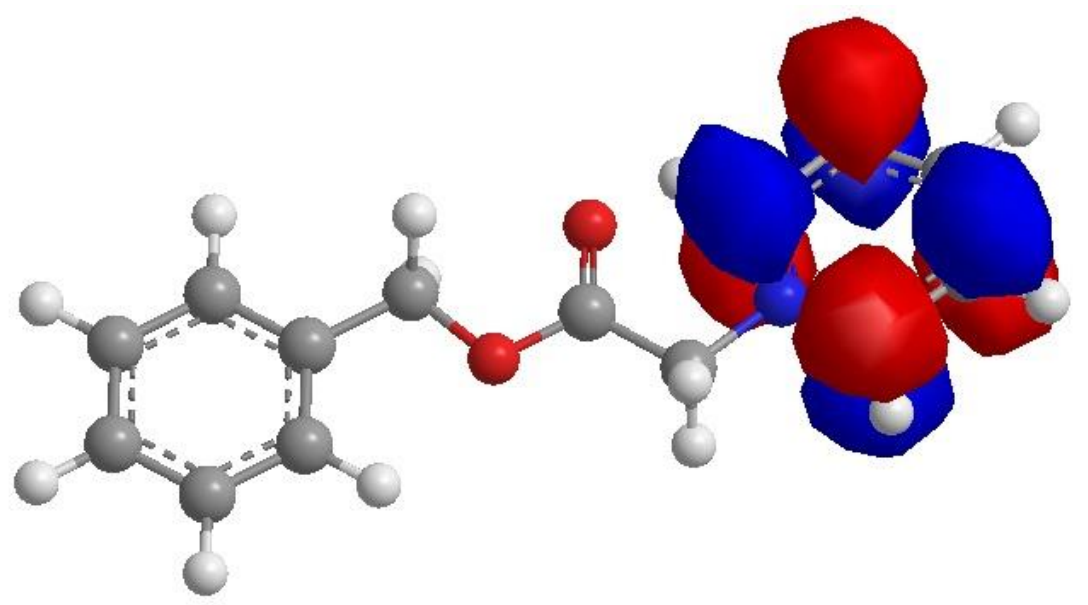

Figure 9: LUMO Orbitals of 5.

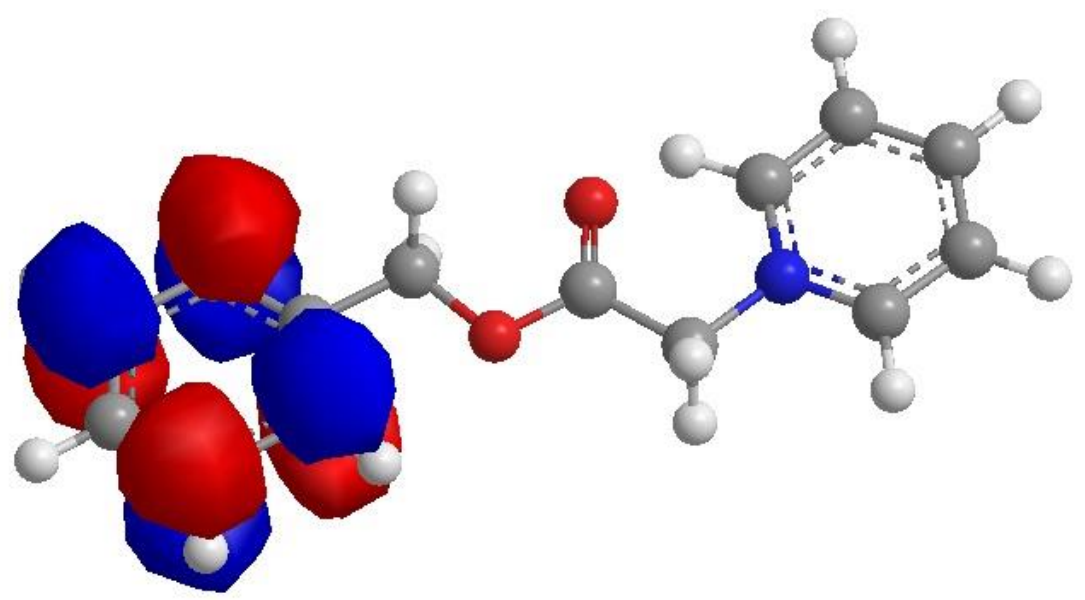

Figure 10: HOMO Orbitals of5.

Table 9: Energy Values of the Global Reactivity and Thermodynamic Parameters for 6 (298.150 K)

\begin{tabular}{|l|c|}
\hline \multicolumn{1}{|c|}{ Parameters, $\mathbf{e V}$} & $\mathbf{6}$ \\
\hline $\mathrm{E}_{\mathrm{LUMO}}$ & -0.013 \\
\hline $\mathrm{E}_{\mathrm{HOMO}}$ & -0.243 \\
\hline $\mathrm{Eg}$ & 0.230 \\
\hline Electronic affinity & -0.013 \\
\hline Ionization potential, & -0.243 \\
\hline$\eta$ & 0.115 \\
\hline$\chi$ & -0.115 \\
\hline$\omega$ & 0.285 \\
\hline$\mu$ & -0.256 \\
\hline $\mathrm{s}$ & 4.347 \\
\hline Dipole moment, Debye & 3.432 \\
\hline Polarizability $(\alpha)$, a.u. & 134.878 \\
\hline
\end{tabular}




\begin{tabular}{|l|c|}
\hline E(UB3LYP), Hartree & -673.092 \\
\hline E (Thermal), kcal/mol & $188.553-$ \\
\hline Entropy $(\mathrm{S}), \mathrm{cal} / \mathrm{mol}-\mathrm{kelvin}$ & 137.442 \\
\hline Heat capacity $(\mathrm{Cv}), \mathrm{cal} / \mathrm{mol}-\mathrm{kelvin}$ & 58.999 \\
\hline
\end{tabular}

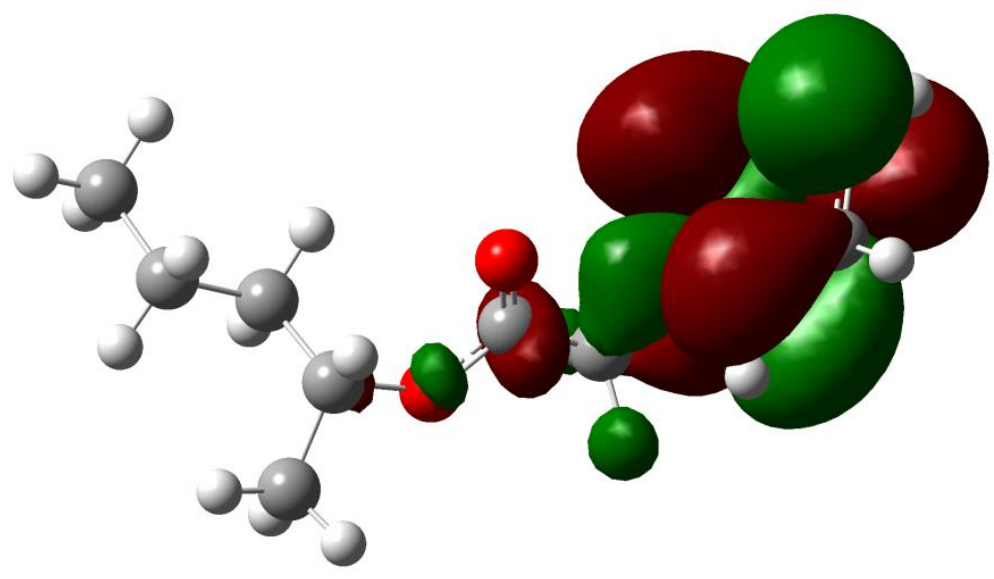

Figure 11: LUMO Orbitals of 6.

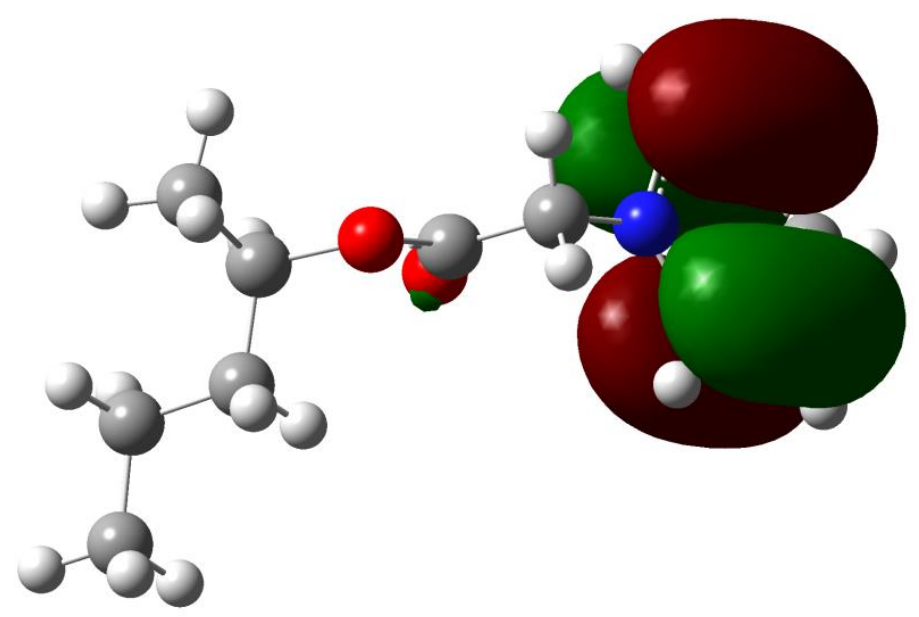

Figure 12: HOMO Orbitals of6.

\section{CONCLUSIONS}

To sum up, the $\mathbf{6}$ types of new quaternary ammonium salts of pyridine and N-butylmorpholine with nonyl, isoamyl, and benzyl esters of chloroacetic acid in the presence of ethyl acetate, acetone and ethanol solvents were synthesized, and their m synthesis methodology was first reported. Their molecular structure was confirmed by IR and $\mathrm{H}^{1}$ NMR experimental spectroscopic methods, and theoretical molecular descriptors and thermodynamic parameters were analyzed by (frontier molecular orbital (FMO) analyses) DFT methods with B3LYP at 6-311G (d,p) basis sets, and the concluded following opinions:

- The reaction between the chloroacetic acid esters and alcohols (nonyl alcohol, isoamyl alcohol, and benzyl alcohol) yield was over $75 \%$ at 1:2 molar ratios.

- It was found that the syntheses reactions of new quaternary ammonium salts are productive when it was 
conducted in an ethanol solvent with over $91 \%$ yield.

- The ionization potential of the synthesized organic compounds ranged, respectively, , suggesting that 2 and 1 have more electronic affinity.

- The energy gap between LUMO and HOMO for the synthesized organic compounds is lower than $0.3 \mathrm{eV}$, suggesting that they have low stability and more reactivity.

- The global electrophilicity index values are in the following variation: showing that 3 and 6 are more acidic than others.

- The heat capacity and entropy of the synthesized organic compounds ranged in the order: which indicates that was high heat capacity and more entropy molecule.

\section{REFERENCES}

1. Joanna Nackiewicz, Effect of quaternary ammonium salts on spectral properties of zinc octacarboxyphthalocyanine, Journal of Molecular Structure. 2019, 87, 127532-127538.

2. R. Li, Z. Wang, Q. Xu, S. Yao, Z. Li, H. Song, Synthesis, characterization and physicochemical properties of new chiral quinuclidinol quaternary ammonium salts, Journal of Molecular Structure. 2020, 87, 127918-127923.

3. Huijun Zhang, Fanghao Ye, Wei Li, Jiaxu Yao, Robert S. Gurney, Dan Liu, ChuanxiXiong, Tao Wang, Bright perovskite lightemitting diodes with improved film morphology and reduced trap density via surface passivation using quaternary ammonium salts, Organic Electronics.2019, 67, 187-193.

4. Y. Zhang, Y. Li, J. Li, Y. Gao, H. Tan, K. Wang, J. Li, Q. Fu, Synthesis and antibacterial characterization of waterborne polyurethanes with gemini quaternary ammonium salt, Science Bulletin. 2015, 60, 1114-1121.

5. More, Neeta, Mukul Barwant, and Archana Hargude. "Determination of Soil Composition-with Relevance to the Physical and Chemical Nature of Black Soil Sample." International Journal of Applied and Natural Sciences (IJANS) 9. 4, Jun-Jul 2020; 114

6. L. Zhang, L. Ren, M. Bai, L. Weng, J. Huang, L. Wu, M. Deng, X. Zhou, Synthesis and biological activities of quinazoline derivatives with ortho-phenol-quaternary ammonium salt groups.Bioorg. Med. Chem., 2007, 15, 6920-6926.

7. Boruń, Conductance and ionic association of selected imidazolium ionic liquids in various solvents: A review, Journal of Molecular Liquids.2019, 276, 214-224.

8. X.-X. Zhao, D. Ge, X. Dai, W.-L. Wu, J.-Y. Miao, B.-X. Zhao, A water-soluble pH fluorescence probe based on quaternary ammonium salt for bioanalytical applications, SpectrochimicaActa Part A: Molecular and Biomolecular Spectroscopy. 2015, $151,218-224$.

9. P. Makvandi, R. Jamaledin, M. Jabbari, N. Nikfarjam, A. Borzacchiello, Antibacterial quaternary ammonium compounds in dental materials: A systematic review, Dent. Mater.2018, 34, 851-867.

10. E. Oblak, A. Piecuch, J. Rewak-Soroczynska, E. Paluch, Activity of gemini quaternary ammonium salts against microorganisms, Appl.Microbiol.Biotechnol.2019, 103, 625-632.

11. Jena, Sandeep Kumar, et al. "Chlorination roasting coupled water leaching process for potash recovery from waste mica scrap using dry marble sludge powder and sodium chloride." International Journal of Minerals, Metallurgy and Materials: 0-0.

12. N. Lu, Y. Fang, Y. Gao, Z. Wei, J. Cao, D. Liang, Y. Lin, H. Duan, Bifunctional Thiourea-Ammonium Salt Catalysts Derived from Cinchona Alkaloids: Cooperative Phase-Transfer Catalysts in the Enantioselective Aza-Henry Reaction of Ketimines, J. Org. Chem. 2018, 83, 1486-1492. 
13. L.M. Ramenskaya, E.P. Grishina, N.O. Kudryakova, Physicochemical features of short-chain 1-alkyl-3-methylimidazolium bis(trifluoromethylsulfonyl)-imide ionic liquids containing equilibrium water absorbed from air, Journal of Molecular Liquids. 2018,272, 759-765.

14. T. Chiba, Y. Hayashi, H. Ebe, K. Hoshi, J. Sato, S. Sato, Y.J. Pu, A. Ohisa, J. Kido, Anion-exchange red perovskite quantum dots with ammonium iodine salts for highly efficient light-emitting devices, Nat. Photon. 2018, 12, 681-685.

15. Q.H. Zhanga, B.S. Houa, Y.Y. Lia, G.Y. Zhua, H.F. Liua,b and G.A. Zhang, Two novel chitosan derivatives as high efficient ecofriendly inhibitors for the corrosion of mild steel in acidic solution, Corrosion Science. 2020, 164, 108346-10842.

16. B.S. Houa, Q.H. Zhanga, Y.Y. Lia, G.Y. Zhua, H.F. Liua,b and G.A. Zhang, A pyrimidine derivative as a high efficiency inhibitor for the corrosion of carbon steel in oilfield produced water under supercritical CO2 conditions, Corrosion Science. 2020, 164, 108334-108340.

17. Cicek, V. O. L. K. A. N., and M. E. H. M. E. T. Ozdemir. "Aqueous corrosion inhibition studies of aluminum 2024, 6061, and 7075 alloys by oxyanion esters of $\alpha$-hydroxy acids and their salts." International J of Applied and Natural Sciences 2.2 (2013): 9-16.

18. Chen-Xiang Wang, Xue-Fen Zhang, A non-particle and fluorine-free superhydrophobic surface based on one-step electrodeposition of dodecyltrimethoxysilane on mild steel for corrosion protection, Corrosion Science.2020, 163, 108284108289.

19. ElyorBerdimurodov, AbduvaliKholikov, KhamdamAkbarov, InnatNakhatov, NigoraKhJurakulova, NurbekUmirov, Adsorption Isotherm and SEM Investigating of Cucurbit [n] Urils Based Corrosion Inhibitors with Gossypol for Mild Steel in Alkaline Media Containing Chloride Ions, Advanced Engineering Forum.2017, 23, 13-20.

20. Wilfred Emoria, Run-Hua Zhanga, Peter C. Okaforc, Xing-Wen Zhenge, Tao Hef, Kun Weif, Xiu-Zhou Lina, Chun-Ru Cheng, Adsorption and corrosion inhibition performance of multi-phytoconstituents from Dioscoreaseptemloba on carbon steel in acidic media: Characterization, experimental and theoretical studies, Colloids and Surfaces A. 2020, 590, 124534-124541.

21. Sharma, Surinder K., Indira R. Samal, and SOUMYA NP. "Urinary Stones in Southern India: Biochemical Analysis and its Clinical Implications." International Journal of General Medicine and Pharmacy (IJGMP) 4.1 (2015): 93-100.

22. ElyorBerdimurodov, AbduvaliKholikov, KhamdamAkbarov, D Nuriddinova, Polarization Resistance Parameters of AntiCorrosion Inhibitor of Cucurbit [N] Urils and Thioglycolurils in Aggressive Mediums, Advanced Engineering Forum. 2018, 26, 74-86.

23. M. Eldesoky, Hala. M. Hassan, Abdu Subaihi, Abeer El Shahawy, and Thoraya A. Farghaly, Water Pipes Corrosion Inhibitors for Q235 Steel in Hydrochloric Acid Medium Using Spiropyrazoles Derivatives, Coatings. 2020, 10, 167-172.

24. Rauf and E. Mahdi, Evaluating Corrosion Inhibitors with the Help of Electrochemical Measurements Including Electrochemical Frequency Modulation, Int. J. Electrochem. Sci. 2012, 7, 4673 - 4685.

25. E. Berdimurodov, K. Akbarov, A. Kholikov, Electrochemical Frequency Modulation and Reactivation Investigation of Thioglycolurils in Strong Acid Medium, Advanced Materials Research. 2019, 1154, 122-128.

26. Abdelaziz S. Fouda, Mohamed A. Ismail, Aliaa M. Temraza and Ashraf S. Abousalem, Comprehensive investigations on the action of cationic terthiophene and bithiophene as corrosion inhibitors: experimental and theoretical studies, New J. Chem. 2019, 43, 768-789.

27. ElyorBerdimurodov, J Wang, AbduvaliKholikov, KhamdamAkbarov, BakhtiyorBurikhonov, NurbikUmirov, Investigation of a New Corrosion Inhibitor Cucurbiturils for Mild Steel in 10\% Acidic Medium, Advanced Engineering Forum.2016, 18, 21-38. 
28. JamshidChuliyev, FeruzabonuYusupova, AbduakhadKodirov, KambaraliTurgunov, ElyorBerdimurodov, Synthesis, X-Ray Characterization, IR Vibrational Frequencies, NMR Chemical Shifts and DFT Properties of 2,7-Dimethyl-2,7-Dicyanide-3,6Diazaoctane, International Journal of Innovative Technology and Exploring Engineering. 2020, 9, 396-404.

29. Saghir Abbas, KhurshidAyub, ManzarSohail, Saqib Ali, Ralf Ludwig, Muhammad Arif Nadeem, Shabbir Muhammad, Synthesis, $X$-ray crystal structure and spin polarized DFT study of high spin Mn based metal-organic framework, Journal of Molecular Structure. 2019, 1175, 439-444.

30. Praveen K. Bayannavar, Madivalagouda S. Sannaikar, S. Madan Kumar, Sanjeev R. Inamdar, Saba Kauser J. Shaikh, Aravind R. Nesaragi, Ravindra R. Kamble, Synthesis, X-ray characterization, DFT studies and Hirshfeld surface analysis of new organic single crystal: 2-(4-Methoxyphenyl)-4-\{[2'-(1H-tetrazol-5-yl)biphenyl-4-yl] methyl\}-2,4-dihydro-3H-1,2,4-triazol-3-one (MTBT), Journal of Molecular Structure. 2019, 1179, 809-819.

31. ThammaratAree, SuchadaJongrungruangchok, Structure-antioxidant activity relationship of $\beta$-cyclodextrin inclusion complexes with olive tyrosol, hydroxytyrosol and oleuropein: Deep insights from X-ray analysis, DFT calculation and DPPH assay, Carbohydrate Polymers. 2018, 199, 661-669. 